\title{
Insights and Perspectives from the PhD to Employee Forum
}

Emily Bell. Research Institute of the McGill University Health Centre Helen Miliotis. University of Toronto Lorna MacEachern. McGill University Luciana Longo. Ryerson University (Previously) Costas Karatzas. Acesis Biomed Inc Ashley Brady. Vanderbilt University

\begin{abstract}
Recent data from Canadian universities show the diverse career outcomes of $\mathrm{PhD}$ graduates in the life sciences (a larger umbrella that includes students from doctoral programs of faculties of medicine). The "From $\mathrm{PhD}$ to Employee Forum" was born out of a pressing need to identify specific solutions to manage the challenge of effectively engaging students in career development during their doctoral degree. To address this challenge, we sought to bring together career development experts to collect insights regarding the approaches of different institutions to address the career planning needs of life science graduate students. Here we summarize key presentations at the forum, review what we see as some of the key challenges in the career preparation of life scientists and summarize three key insights raised in the forum.
\end{abstract}

\section{Background}

In a career outcomes study of $\mathrm{PhD}$ graduates, the University of Toronto's 10,000 PhDs Project identified forty-five percent of life science PhDs employed outside of the postsecondary education sector (The School of Graduate Studies, ND). At another Canadian university, seventeen percent of $\mathrm{PhD}$ graduates from the faculty of medicine held research intensive faculty positions, including up to 11 years after graduation (University of British Columbia PhD Outcome Study, 2016). Research suggests that during the $\mathrm{PhD}$, students may consider both research and non-research related careers at the same time, or have career preferences change throughout their studies (Fuhrmann, Halme, O'Sullivan, \& Lindstaedt, 2011). The Conference Board of Canada report entitled, "Inside and Outside the Academy: Valuing and Preparing PhDs for Careers," indicates that the transition to full employment for $\mathrm{PhD}$ graduates can take up to four or five years (Edge \& Munro, 2015). In the US, data from the National Science Foundation, National Center for Science and Engineering Statistics Survey of Earned Doctorates, show that $35.5 \%$ of life science doctoral recipients have no definite commitment for employment or postdoctoral study at graduation (National Science Foundation, 2018).
Taken together, these data points challenge notions of there being one typical career path for life science PhDs. Instead, we can imagine that many $\mathrm{PhDs}$ will transition to employment in non-faculty roles, outside of the postsecondary sector, and that they may need to apply significant effort and persistence in their job search.

Staggering scientific advances mean that the life science sector is undergoing a period of immense technological innovation. There is a simultaneous shift in the talent pool needed in the sector including towards more data science and analytical experts (Randstad USA, 2020). The enhanced speed of new discoveries is being matched by changing business models and regulatory considerations, and initiatives to move treatments to market more quickly. Employers in the life sciences need workers, who alongside other specialized skills, understand industry and industry processes (including regulations, design and conduct of trials, manufacturing and control), and possess soft skills for interdisciplinary teamwork and collaboration (Nugent \& Kulkarni, 2013). In 2019 , the following were predicted to be some of the most in-demand 
roles in the life sciences: clinical trial managers, drug safety specialists; medical writers; and regulatory affairs associates (Randstad USA, 2019).

\section{Forum Objectives}

The "From PhD to Employee Forum" (June 13 ${ }^{\text {th }}, 2019$ ) was born out of a pressing need to identify specific solutions to improve the career preparedness of graduate students in the life and health sciences in Montréal, Quebec. To address this challenge, we sought to bring together career development experts, including invited speakers from the US and Ontario, to collect insights regarding the approaches of different institutions to address the career planning needs of life science graduate students.

The objectives of the forum were to:

1. Share best-practices of how to prepare graduate students for their future careers, drawing on local, national and US examples.

2. Explore the use of targeted professional skills training to broaden students' exposure to career paths.

3. Identify opportunities for collaboration between centers at the local, provincial and national level.
Various Approaches are Used to Engage Life Science Graduate Students in Career Development

From each speaker's presentation of a program of career development offered to their students, we have summarized the key take-aways below. We have broadly grouped our summaries of the programs presented at the Forum into i) those where students voluntarily participate and ii) that where students were required to participate as a component of their degree.

\section{Programs where Students Participate Voluntarily (3 programs presented at the Forum)}

Vanderbilt University's ASPIRE Program for graduate students and postdocs in the School of Medicine

Presenter: Ashley Brady, PhD Assistant Dean of Biomedical Career Engagement and Strategic Partnerships, Assistant Professor of Medical Education and Administration, Vanderbilt University, School of Medicine.

Description. In 2012, Vanderbilt University was awarded a National Institutes of Health: Broadening Experiences in Scientific Training (BEST) Award, to facilitate the investigation and piloting of new approaches to enhance career and professional development for graduate students and postdoctoral fellows (Petrie, Brady, Stuart, Brown, \& Gould,
2020). Dr. Ashley Brady, Assistant Dean of Biomedical Career Engagement and Strategic Partnerships, presented the scope of the ASPIRE Program, which serves the $\approx 650 \mathrm{PhD}$ students and $\approx 350$ postdoctoral fellows within the School of Medicine at Vanderbilt University.

The ASPIRE Program includes a diverse provision of services (i.e. individual advising and resource development), internships/externships, events and programs. For example, over the previous five years, the ASPIRE Program had offered 13-modules (i.e. non-credit elective short courses) in collaboration with ten different teaching partners, which cover topics in communication, teaching, clinical research, business \& entrepreneurship and data science (Petrie, Carnahan, Brown, \& Gould, 2017; Colby, Wheeler, Petrie, Gould, \& Schmitz, 2020). For a more interactive experience, many of these courses also have a project-based learning component. In order to best serve their students and postdoctoral fellows, some modules are offered annually or even twice a year, while others are offered every other year. New modules are created, while others have been phased out to best to address the evolving needs and interests of the students. Up to the date of the forum, more than 800 students had participated in the ASPIRE modules.

For most of the ASPIRE modules, students commit 1-2 hours of time per-week to an 8-week long course. However, there is flexibility in these modules 
Figure 1

Scope of the ASPIRE Program

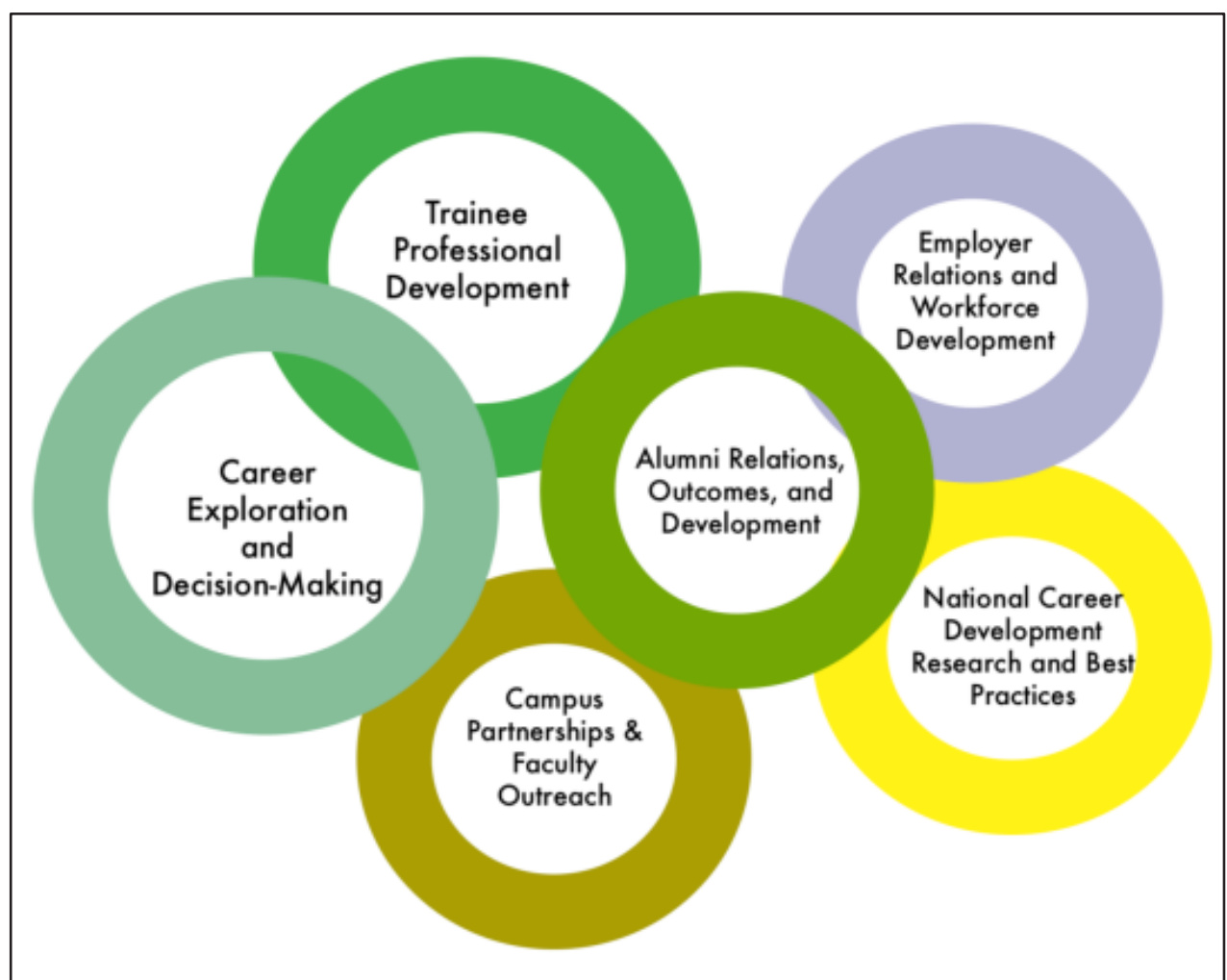

and each has its own flavor. For example, the courses range from 2-32 total sessions and the capacity of each course varies from 5 , to an unlimited number of, participants.

\section{Selected results/outcomes} (unpublished). Individual course outcomes indicate that students agreed (or strongly agreed) that the modules had positive outcomes (e.g. provided knowledge to help guide career decisions and were a valuable use of time). Counteracting some common misperceptions, Dr. Brady shared that, in general, evaluations of the ASPIRE program demonstrate that:

- Participation does not prolong time to defense;
- Engagement does not result in reduced publication productivity of students.

\section{Other achievements.}

Funded by a 2016 and 2018

"Career Guidance for Trainees Award" from the Burroughs Welcome Fund for their Management and Business Principles for Scientists (Petrie, Brady, Stuart, Browen, \& Gould, 2017) and Data Science Essentials ASPIRE Modules, respectively.

\section{Peer Career Program for graduate students and postdocs in the life sciences at the Re- search Institute of the McGill University Health Centre}

Speakers: Emily Bell, PhD, Manager of the Desjardins Centre for Advanced Training of the RI-MUHC, Lorna MacEachern, MA BA, Career Advisor, Graduate students $\&$ postdocs, $\mathrm{Ca}$ reer Planning Service, McGill University.

A collaboration between the RI-MUHC's Desjardins Centre for Advanced Training (DCAT) and McGill University's Career Planning Service, prompted the first official offering of the Peer Career Groups Program in 2016. Dr. Emily Bell and Ms. Lorna MacEachern created this structured career development program, focusing on peer support, to address the following:

- The job landscape has changed, making graduate student trainees feel uncertain about the future;

- Students feel isolated and uniquely challenged in career planning;

- The demands of graduate school often lead to procrastination and negative emotions related to career planning;

- The transition from academia can be challenging.

To tackle these challenges, they were inspired by a program that had been used at Yale Uni- 
Figure 2

Peer Career Program structure

(3.9/5 in the first year of offer on the question "What extent did the program help you move forward in your career"), trainees continued to struggle with:

- Obtaining a deep knowledge of specific career fields;

- Connecting their skill and interest profiles to potential career options;

- $\quad$ Being accountable to their peers within their groups;

- Letting unrealistic beliefs guide their

Description. A cohort of 30-50 trainees are enrolled in the program and assigned to peer triads, which are formed based on the stage of the trainee and location in which they want to meet their peers. A series of five facilitator-led workshops are held during the program for all participants. Between the workshops, students work on assigned activities and meet with their peer group to discuss, share and reflect on the workshop content and activities.

\section{Selected results/outcomes} (unpublished). Observations from the first three cohorts of the PCG program revealed that despite positive overall evaluations career decisions (e.g. there is
only one right career-choice).

In response to this feedback, the facilitators have made several adaptations to the program. These changes include: incorporating more interactive workshops (e.g. completing career research in class); exposing trainees to Stanford University's “Designing Your Life" principles (e.g. reframing, no one right path, prototyping options for your career) (Burnett and Evans, 2016), and facilitator 'dropins' on the peer group meetings to help guide trainees in their reflection. Moreover, one of the biggest gaps identified by trainee partici- 
pants was insufficient acquisition of career knowledge in specific career areas of interest. To address this gap, the 2019 program will be divided into two stages. In stage 1 , trainees will focus on career discovery (the format of this stage remains the same as described above). In Stage 2, trainees will focus on increasing career knowledge in targeted areas of interest (e.g. scientific communication, management, consulting, business of science, clinical trials).

Other achievements. In 2019, the Desjardins Centre for Advanced Training was funded by a "Career Guidance for Trainees Award" from the Burroughs Wellcome Fund for their Clinical and Regulatory Affairs training program (not discussed here).

\section{Ryerson University's}

Industry Insights and Navigating Networks for Graduate Students in the Faculty of Science

Speaker: Luciana Longo, BA, CCDP, Career Education Specialist, Graduate Students, Faculty of Science, Ryerson University

Description. Ryerson University's Industry Insights and Navigating Networks (IINN) program was established in 2016 as a collaboration between the Faculty of Science and the Career \& Co-op Centre. The IINN program aims to equip graduate students within the Faculty of Science with more information about the labour market in specific areas by providing a job shadowing experience. Modules are provided by the Career \& Co-op Centre in advance of the job shadowing, which teach students how to: conduct labour market research, write a value proposition and connect with appropriate professional associations. During the job shadowing ( 80 science graduate students and around 70 professionals within 40 organizations have participated) students learn onsite about their career field of interest. Flexibility allows for both organizations or individual professionals to engage students in a variety of ways, including conducting informational interviews onsite, assigning a job simulation, conducting an organizational tour, or hosting an onsite informational session.

Following the job shadowing, students are encouraged to complete reflective exercises, allowing them to digest what they have learned and create an action plan. For students, these experiences provide valuable exposure to organizations, broaden their network, make them aware of career possibilities and sensitize them to the ways that companies work and the skills that they value.

\section{Selected results/outcomes (unpublished).}

- $100 \%$ of graduate students stated they would recommend the program to other students;

- $79 \%$ of graduate students felt the IINN program is important to extremely important for their long-term career planning;
- $71 \%$ of graduate students stated they would rate their overall experience as good or excellent;

- $67 \%$ of graduate students felt that the key tangible career development outcome of the job shadow was learning which skills are in demand.

Programs where Students are Required to Participate as Part of Their Degree Requirements (1 program presented at the Forum)

\section{The University of Toronto's Department of Physiology Seminar Course on Graduate Professional Development}

Speaker: Helen Miliotis, PhD, Assistant Professor and Director of Graduate Professional Development in the Department of Physiology, Faculty of Medicine, University of Toronto

Dr. Helen Miliotis is an Assistant Professor in the University of Toronto's Department of Physiology and leads the department's seminar course on graduate professional development (started in 2017). The seminar course is optional for current graduate students and mandatory for new $\mathrm{PhD}$ students. Students enrolled in the MSc degree are also encouraged to take the course. Despite the fact that the course is a requirement for students in the physiology graduate program, the class size is kept as small as possible (usually about 10-15 students per term). 
Description. As part of the seminar course, students are exposed to various topics related to career and professional development and are required to complete specific assignments, where they must receive at least a $75 \%$ on each assignment to pass the course. Sample topics include: communication (e.g. writing a research summary, preparing for the 3 Minute Thesis); strategic marketing (e.g. creating a LinkedIn profile, networking effectively); wellness work (e.g. work-life balance); job searching (e.g. preparing cover letters, resumes, being successful in the job interview); career exploration (e.g. conducting informational interviews, learning from guest panelists). Some of the specific elements that students are evaluated on include: written reflections on required readings and course activities, active participation in class activities and events (i.e. career panels, networking events) and the preparation of documents for a targeted job application (i.e. cover letter and resume).

\section{Selected results/out-} comes (unpublished). According to a pre-post assessment, where students ranked their skills on a five-point scale before and after the course, students generally indicated a positive impact of the course on skill acquisition in a number of career and professional development areas (e.g. job search strategies, networking skills, cover letter and resume skills, professional online presence). More students also felt better prepared to enter the job market after taking the course, relative to how they felt before the course.

\section{Common Career Development Challenges and Suggested Solutions Identified by Participants}

Three overarching career development challenges were identified and discussed at length during the forum: (1) how to collect and interpret outcomes; (2) how to tackle general skills deficiencies and unmet employer skill needs; and (3) how to engage more students in career development programs. Below, we have summarized several key insights raised regarding each of these challenges and the potential solutions proposed by participants.

\section{Reflection \#1: How to Collect and Interpret Outcomes}

\section{Why Collect Career Development Outcomes:}

The NIH BEST program (Broadening Experiences in Scientific Training, 2019) suggests that there are several important reasons to evaluate career development outcomes:

- "Offer new or prospective students greater transparency in training and career outcomes;

- Track alumni so they may assist with professional development opportunities for students and postdocs;

- Identify career mentors for current doctoral students;
- Facilitate continuous program improvements and academic program review;

- Support training grant application needs and accreditation requirements."

Best-practices have also suggested that evaluation outcomes for University Career Centres should include usage statistics, satisfaction, feedback, pre-post skills assessment, evaluation of documents and graduate career outcomes. Although there is no one right way for Career Centres to measure their success, career centres may regularly evaluate services used and student satisfaction measures to improve services and measure outcomes for students (Benzinger, Kerford, Lumsden, Mahoney, Rodney, \& Keates, 2011; Bowness, 2019).

\section{Challenges identified regarding career outcome} assessment. Several aspects related to outcome collection and interpretation were viewed as particularly challenging among participants. These include difficulty in carrying out assessments for both career development programs and individual student career paths, comparing outcomes between programs and/or institutions, and identifying sufficient resources and expertise for conducting assessments. Different incentives seemed to drive how, what, and why programs and institutions assess outcomes. For instance, the presenters who provided assessment data identified different goals for evaluating the outcomes of their respec- 


\section{\begin{tabular}{l|l} 
& Insights and Perspectives \\
\hline 100 &
\end{tabular}}

tive programs, such as: securing internal buy-in, providing evidence to support the continuation of funding or acquisition of new funding, convincing new students to enroll, or reassuring supervisors about impacts on student progress. Moreover, not only did the reason for collecting outcomes differ between institutions, but so too did the metrics used to assess these outcomes, making objective comparisons of the different approaches used between and across centres very difficult. For our participants, much of the challenge of outcome assessment stemmed from the fact that there was a lack of integration between departments (e.g. career planning and alumni services) and institutions (e.g. Graduate Studies Faculties), which limits the ability to track students effectively.

\section{Suggested Solutions.}

- Institutions and programs should collect more prospective and/or qualitative, in-depth information about career outcomes instead of just quantitative assessments. Some examples from which to draw inspiration include the inclusion of written or multimedia-based alumni profiles [eg., Beyond the Lab by the BRET Office (BREAT Office of Career Development, ND)] or tracking graduate students via the TRACE program that includes the collection of stories from graduates (TRaCE McGill, ND).

- To increase the utility of career development outcomes for current $\mathrm{PhD}$ students exploring different career opportunities, the types of questions asked during assessment could be broadened to include questions such as: are you happy in your current career; how long did it take you to get to this point; what was the transition like; how did we prepare you (as a program or institution); how do you think you got this job; what extracurricular activities did you do as a student that you feel played a role in your transition; do you use your graduate skills or qualifications in your current position?

- For comparison among life science institutions or programs, those conducting career outcome assessments should follow the common taxonomy developed by the Coalition for Next Generation Life Sciences (2017) whenever possible. The RI-MUHC piloted such a career-outcomes tracking initiative in 2017 and found that they were able to locate and classify $80 \%$ of trainees who graduated between 2009-2012. A common taxonomy would facilitate comparisons to be made across different career centers and institutions.

- Assessments would benefit from more communication between centres, programs, institutions, and governments to ensure that the collected data has broad value.

- Already available tools for assessment could be used to mitigate the need to 're-invent the wheel', or to support staff with ittle experience or training in evaluating career development outcomes (Benzinger, et al, 2011; CERIC, 2017) Similarly, sharing data and evaluation approaches in venues such as this Forum or the annual meeting of the Graduate Professional Development Network, may prove to be a valuable professional development opportunity for staff and administrators to learn more about different assessment strategies employed and to establish new collaborations.

- Finally, it was suggested that provincial or federal funding mechanisms to support outcomes tracking could encourage data sharing, the development of common taxonomies, and support the high resource burden of collecting data.

\section{Reflection \#2: How to Tackle General Skills Deficiencies and Unmet Employer Skill Needs}

\section{Skill Deficiencies Identified by Employers}

Asked in qualitative interviews by the Council of Graduate Schools about any skill deficiencies they see in recent STEM PhD and MSc graduates, employers noted different disciplinary and interdisciplinary skills. The report identified the most common general skills gaps as being:

- "Writing, speaking, and presentation skills, including effective PowerPoint usage;

- Cross-disciplinary and 
cross-cultural communication and teamwork;

- Time management and project management in an experiential context" (Denecke, Feaster, \& Stone, 2017).

\section{Challenges Identified} Regarding Skill Deficiencies. Targeted competencies have been described for the masters and doctoral degree pursued in Quebec which include essential competencies in the areas of professional and scientific production, knowledge and critical view, communication and ethics and integrity (Association des doyens des etudes supérieures au Qubec, 2015). Despite this, it was the perspective of the participants that graduate students require more training in certain key skills to be successful in today's life sciences sector. Soft skills, such as communication, negotiation, networking, and adaptability were highlighted by participants as transferable skills that will benefit students regardless of their chosen career. The challenges discussed for institutions, graduate programs, or professional and career development programs were both how to identify specific skills gaps among graduates and how to enrich both soft and hard skills in order to better equip students for employment success in the changing life sciences sector.

\section{Suggested Solutions.}

- Participants generally rejected a 'one-size fits all' approach to skills development. Rather, discussion emphasized the need for students to be able to: reflect and assess their own competencies, strengths and interests; compare skills with career profiles; identify gaps by interacting with employers or industry; and act on filling these gaps by implementing effective career planning. Such a process amounts to completing an individual development plan (IDP), which some institutions (e.g. McGill University and the University of Alberta) and the Canadian Institutes of Health Research (Canadian Institutes of Health Research, 2019) have advocated, or routinely implemented, for graduate students.

- Career centers would benefit from frequent industry, employer, and alumni (or professional) engagement and dialogue with regards to skills of graduates, curriculum or programs. Specific actionable solutions include: career centers sending questionnaires to professionals who participate in career events, establishing advisory groups to revise curricula or create new programs that include industry representation, or asking alumni about skills they have needed to develop since graduation.

- Incorporation of tested approaches to improve soft skills that have been employed for medical education (e.g. use of multiple-mini-interviews (MMI) as an interactive means of improving communication and adaptability) should be considered and could be tailored for, or applied directly to, a graduate student career development context.

- Diverse mentorship opportunities (i.e. diverse in respect to career roles, stage of career, culture, gender etc.) should be made available to students to sensitize them to potential skills gaps. These mentors can also provide valuable feedback about the quality of training and gaps observed in the pool of trainees.

- Students should be able to access experiential opportunities that will allow them to employ and improve skills. For instance, Mitacs, which provides funding for graduate students to conduct research in both an academic and industry setting, has demonstrated success in transitioning graduates to employment. Other experiential programs exist across the country (Mayne, 2019; Transformative Talent Internship, ND).

- On a larger scale, engagement of governments (provincial and national) and the life sciences industry in discussions around R\&D funding in Canada to encourage innovation in the life sciences industry should be promoted by career centers. Such initiatives could provide important insights regarding how to align the skillsets of PhD graduates with current job opportunities. 


\section{Reflection \#3: How to Engage More Students in Career Development Programs}

\section{Challenges Identified Regarding Student Participation}

One of the challenges experienced by career development programs in which students participate voluntarily, is engaging those who could benefit from career support. As an example, although the Desjardins Centre for Advanced Training (DCAT) sees approximately $40-50 \%$ of trainee participation across a year of events, that number is much smaller for individual activities (4$10 \%$ ). Another concern relayed by some participants was that many students participate too late in their degree, when there is little time to make career transitions, resulting in much more stress. The reasons why students do not participate earlier are not clear. At the same time, it has been the experience of the participants that engaging postdoctoral fellows (PDFs) can also be challenging. Fewer than $10 \%$ of DCAT participants are identified as PDFs. Some of the factors that may influence trainee participation are: permission or endorsement by their PI (i.e. does their PI prevent them in subtle or explicit ways from attending events); timing or location (is it convenient/do trainees have conflicting experiments or family considerations); advertisement and awareness (are students adequately informed about various career-development offerings available to them).

\section{Suggested Solutions.}

- Greater education of PIs was viewed as essential for engaging students in career development programs. Thus, efforts could be made by career development professionals to make PIs familiar with program offerings and with data on career outcomes of students. Additionally, there may be other ways that career development programs can support PIs who want to have conversations with their students about career possibilities. For instance, career development professionals could better educate PIs about individual development plans (IDPs) and how to have productive conversations around the IDP; help PIs to increase their non-academic networks and help guide PIs around difficult conversations with students (e.g. encouraging careers outside of academia if they feel that would suit their trainee).

- One assessment metric that career development professionals should collect, and present to PIs, is convincing data about how student participation in career development activities does not lengthen time to degree completion.

- Career development programs and modules should indicate the tangible benefit that individual students will achieve/ acquire through their participation in the program (e.g. a cover letter, a revised $\mathrm{CV}$, a small piece of career research on a company that interests them, an improved LinkedIn profile). These individual deliverables could attract more students than programs that state intended group outcomes.

- Enhancing the diversity in programs offered, methods of delivery, language(s) of delivery, modes of advertisement (e.g. posters, social media, e-mails) and locations of events/activities may result in increased student engagement. Participants recognized that different à la carte offerings should be available that are developed and tailored to the needs of the local community.

- Finally, harnessing feedback from local student groups may be another way to enhance engagement. This could be accomplished through either partnering with student groups in the development of offerings, or by having a presence at relevant student association events (e.g. career panels). This is an outreach strategy that some participants have already employed (e.g. attendance at student organized research days, new student orientations) that has yielded success.

\section{Summary}

The first PhD to Employee Forum was hosted by the Desjardins Centre for Advanced Training (DCAT) of the Research Institute of the McGill University Health Centre (RI-MUHC) in Montréal Quebec on June 13, 2019. The purpose of this Forum was to 
prompt discussion among, mainly local, stakeholders about the career preparation of graduate students in the life sciences in our region. Three overarching challenges were identified during the forum: (1) how to collect and interpret outcomes; (2) how to tackle general skills deficiencies and unmet employer skill needs; and (3) how to engage more students in career development programs. In this article we have expanded on the reflections on these three topics shared at the Forum with the hopes that it will help guide other health research institutions who wish to develop career initiatives for their students. Participants generally thought that open-forum discussions, such as the PhD to Employee Forum, serve as an important networking opportunity for career development professionals and stakeholders across institutions and have the potential to increase collaboration among institutions.

\section{Acknowledgements}

We would like to thank participants of the Forum for sharing their thoughts, perspectives and experiences. We would also like to thank Dr. Miguel Burnier $\mathrm{Jr}$, Co-Directors of the Desjardins Centre for Advanced Training, for their input into the Forum activities, Miss Christina Farant for organizing this activity, and Dr. Necola Guerinna for help in structuring and editing this report.

\section{References}

Ad hoc Working Group, Association des doyens des études supérieures au Québec. Targeted Competencies in Graduate Programs. May 15, 2015. http://adesaq.ca/wp-content/up loads/R\%C3\%A9f $\%$ C3\% A9rentiel-de-comp $\% \mathrm{C} 3 \% \mathrm{~A}$ 9tences-ADESAQ-FINALE_English.pdf (Accessed December 17, 2019).

Benzinger K, Kerford K, Lumsden L, Mahoney K, Rodney Y, Keates C. 2011. University Career Centre Metrics Working Group, Canadian Education and Research Institute for Counselling. Career Centre Evaluation: A Practitioners Guide. https://ceric.ca/careercentreevaluation/resources/ Complete_text_Evaluation_ Guide.pdf

Bowness S. Campus Career Centres Step up to Better Serve Students. University Affairs, February 20, 2019. https:// www.universityaffairs.ca/features/feature-article/campuscareer-centres-step-up-to-better-serve-students

BRET Office of Career Development, Vanderbilt University. Beyond the Lab Series. https:// medschool.vanderbilt.edu/career-development/beyond-thelab-see-listen/

Broadening Experiences in Scientific Training. Tracking participation and Evaluating Outcomes. http://www.nihbest.org/build-career-development-program/tracking-participation-evaluating-outcomes/
(Accessed December 17, 2019)

Canadian Institutes of Health Research, Individual Development Plan Form http://www. cihr-irsc.gc.ca/e/documents/ training_idp_form-en.pdf (Accessed December 17, 2019).

CERIC. Evaluation and Best Practices of Career Services, Literature Search Updated April 2017. https://ceric. ca/wpdm-package/evaluation-and-best-practices-of-career-services/

Coalition for Next Generation Life Science. http://nglscoalition.org/coalition-data/

Colby JM, Wheeler FC, Petrie KA, Gould KL, and Schmitz JE. Institutional Training Opportunities for $\mathrm{PhD}$-Students in Laboratory Medicine: An Unmet Career-Development Need? (2020) The Journal of Applied Laboratory Medicine. Journal of Applied Laboratory Medicine. 5(2): 412-416. PMID: 32445389, PMCID: PMC7055666

Denecke D, Feaster K, Stone K. 2017. Professional Development: Shaping Effective Programs for STEM Graduate Students. Washington, DC: Council of Graduate Schools. Edge J., and Munro D. The Conference Board of Canada. Inside and Outside the Academy: Valuing and Preparing $\mathrm{PhDs}$ for Careers. November 24, 2015.

Fuhrmann CN, Halme DG, O'Sullivan PS, Lindstaedt B. 2011. Improving graduate education to support 
a branching career pipeline: recommendations based on a survey of doctoral students in the basic biomedical sciences. CBE Life Sci Educ. 10(3):239-49.

Mayne P. Programs showcase grad student skills to employers. Western News. August 12, 2019. https://news.westernu. ca/2019/08/programs-showcase-grad-student-skills-toemployers/

National Science Foundation, National Center for Science and Engineering Statistics. Doctorate Recipients from U.S. Universities: 2017, Survey of Earned Doctorates. December 4, 2018.

Nugent K.L., Kulkarni A. (2013) An interdisciplinary shift in demand for talent within the biotech industry. Nature Biotech, 31:9, 853-855.

Petrie KA, Brady AE, Stuart KFZ, Brown AM, and Gould KL. Vanderbilt's ASPIRE program: building a strong career development foundation to change the Ph.D.-training culture. In: Infante Lara L, Daniel L, and Chalkley R, (eds). BEST: Implementing Career Development Activities for Biomedical Research Trainees. San Diego: Academic Press, 2020: 199-213.

Petrie KA, Carnahan RH, Brown AM, Gould KL. (2017) Providing Experiential Business and Management Training for Biomedical Research Trainees. CBE Life Sciences Education. 16(3). pii: ar51. doi: 10.1187/cbe.17-05-0074.
PMID: 28798213

Randstad USA. Life sciences 2019 trends. https://rlc.randstadusa.com/for-business/ learning-center/salary-trends/ life-sciences-2019-trends (Accessed December 17, 2019)

Randstad USA. Under pressure to innovate, life sciences employers need to close skills gap during a transitional time https://www.randstad.com/ workforce-insights/future-ofwork/under-pressure-to-innovate-life-sciences-employers-need-to-close/ (Accessed December 16, 2020)

The School of Graduate Studies, University of Toronto. 10,000 PhDs Project. https://www. sgs.utoronto.ca/about/exploreour-data/10000-phds-project/ TRaCE McGill, Graduate and Posdoctoral Studies, McGill University. https://www.mcgill.ca/gps/students/trace

Transformative Talent Internship, Faculty of Graduate Studies, University of Calgary.https:// www.ucalgary.ca/mygradskills/ internships

University of British Columbia PhD Career Outcome Survey 2016. https://outcomes.grad.ubc. ca (Accessed on December 16, 2020) 